\title{
Internal Friction on AISI 304 Stainless Steels with Low Tensile Deformations at Temperatures between -50 and $20^{\circ} \mathrm{C}$
}

\author{
T. F. A. Santos ${ }^{1}$ and M. S. Andrade ${ }^{2}$ \\ ${ }^{1}$ Departamento de Engenharia de Materiais, Universidade Estadual de Campinas (Unicamp), \\ C.P. 6122, 13083-970 Campinas, SP, Brazil \\ ${ }^{2}$ Setor de Tecnologia Metalúrgica, Fundação Centro Tecnológico de Minas Gerais (CETEC), \\ Avenida José Cândido da Silveira, 2000, 31170-000 Belo Horizonte, MG, Brazil \\ Correspondence should be addressed to M. S. Andrade, margareth.spangler@cetec.br
}

Received 5 March 2010; Revised 19 May 2010; Accepted 14 June 2010

Academic Editor: Paolo Colombo

Copyright ( $) 2010$ T. F. A. Santos and M. S. Andrade. This is an open access article distributed under the Creative Commons Attribution License, which permits unrestricted use, distribution, and reproduction in any medium, provided the original work is properly cited.

\begin{abstract}
Austenitic stainless steels specimens were deformed by tension in temperatures in the range of $-50^{\circ} \mathrm{C}$ to $20{ }^{\circ} \mathrm{C}$ and 0.03 to 0.12 true strain, in order to obtain different volumetric fractions of $\varepsilon$ (hexagonal close packed) and $\alpha^{\prime}$ (body centered cubic) strain induced martensites. The morphology, distribution and volumetric fractions of the martensites were characterized by metallography and dilatometry analysis and quantified by ferrite detector measurements. The damping behavior of specimens with different volumetric fractions of martensites was studied in an inverted torsion pendulum in the $40^{\circ} \mathrm{C}$ to $400^{\circ} \mathrm{C}$ range. The $\varepsilon$ and $\alpha^{\prime}$-martensites reversion was observed in the temperature range of $50^{\circ} \mathrm{C}-200^{\circ} \mathrm{C}$ and $500^{\circ} \mathrm{C}-800^{\circ} \mathrm{C}$, respectively, by dilatometry. Internal friction curves in function of temperature of the deformed samples presented internal friction peaks. The first internal friction peak is related to sum of the amount of $\varepsilon$ - and $\alpha^{\prime}$-martensites. For low deformations it aligns around $130^{\circ} \mathrm{C}$ and it is related only to the $\varepsilon \rightarrow \gamma$ reverse transformation. The peak situated around $350^{\circ} \mathrm{C}$ increases with the specimen degree of deformation and is, probably, related to the presence of $\alpha^{\prime} / \gamma$ interfaces, and deformed austenite.
\end{abstract}

\section{Introduction}

Austenitic stainless steels have a complex mechanical behavior at room temperature. Generally, behavior differences are associated to a higher or lower stability related to martensite transformation $[1,2]$. Depending on the chemical composition and work temperature, austenitic stainless steels may form, when deformed, $\varepsilon$ and $\alpha^{\prime}$ martensite phases of hexagonal close-packed and body-centered tetragonal crystal structures, respectively [3-7]. The formation of $\varepsilon$ and $\alpha^{\prime}$, depends on the stacking fault energy which is related to the chemical composition, the quantity, and temperature of deformation [6].

The strain-induced martensites change the steel mechanical behavior, for example, the austenitic stainless steels formability, one of the demanded properties of this steel in industrial applications $[8,9]$. Because of this, the austenitic stainless steel is an object of continuous studies. This paper evaluated the damping behavior of mechanical vibrations on the AISI 304 austenic stainless steel due to the different quantities and kinds of strain-induced martensites.

Studies by X-ray diffraction $[6,10]$ in an AISI 304 austenic stainless steel showed that when the relative volumetric fraction of the $\varepsilon$-martensite reaches the maximum quantity close to 0.05 of true deformation, and so it diminishes, while $\alpha^{\prime}$-martensite increases with deformation increment. Petit et al. [11] show that the amount of $\mathcal{E}^{-}$ martensite at the initial stage of straining is almost as large as the amount of $\alpha^{\prime}$-martensite. Nevertheless, the $\varepsilon$-martensite decreases near to zero when $\alpha^{\prime}$ reaches a maximum at $10 \%$ strain. De et al. [12] had indicated through $\mathrm{X}$-ray measurements that the formation of $\varepsilon$-martensite was favored over $\alpha^{\prime}$-marteniste during initial straining.

Increasingly, steels used in modern automobilist production require rigorous chemical control procedures. The carbon control is particularly important, once the strength 


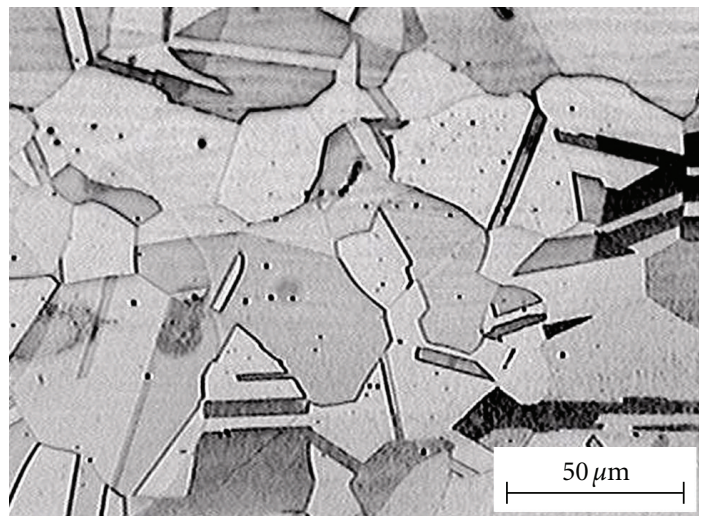

(a)

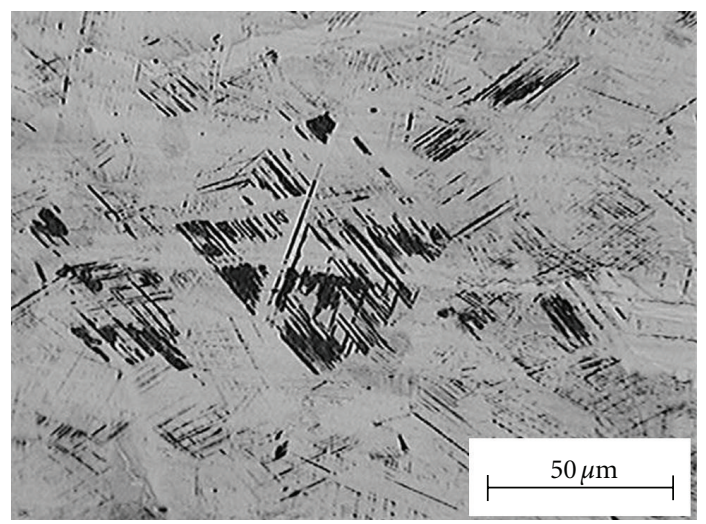

(b)

Figure 1: (a) Photomicrograph of a 304 sample as received. Etching: Glyceregia reagent. (b) Photomicrograph of a sample with true deformation of 0.03 at $-10^{\circ} \mathrm{C}$. Etching: Beraha II reagent.

and formability of the steel can be affected by the presence of this element. Traditionally, carbon atoms in solid solution were measured initially by the internal friction technique, based on the phenomenon described by Snoek, on which internal friction peaks are produced on a steel sample, with small carbon additions, submitted to an elastic oscillating tension.

The internal friction can be defined as the capacity of a material to damp mechanical vibrations. The change of capacity of a material to damp mechanical vibrations as function of time or temperature corresponds to a microstructural, substructural, or structural change [13].

The internal friction technique or the mechanical relaxation spectroscopy emerged around the 1940's, based on the Snoek effect $[13,14]$. This effect is caused by the redistribution of solute atoms in octahedral sites of bodycentered cubic metal (BCC) submitted to an oscillating tension. When a BCC metal is submitted to a tension, in the elastic regime, the elastic deformation appears with a temporal delay. As a consequence, interstitial atoms jump among interstitials sites of the crystalline structure, and an anelastic deformation emerges. The internal friction peak height gives information about the phenomenon intensity which causes the damping [14]. In the case of a steel sample

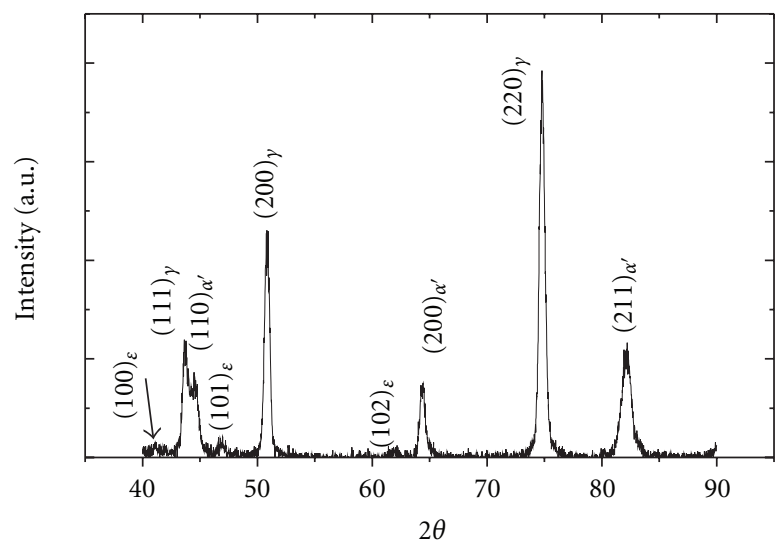

FIGURE 2: X-ray diffraction spectrum of sample deformed of 0.06 at $-10^{\circ} \mathrm{C}$.

with small additions of carbon, the internal friction peak, also called Snoek peak, is related to the quantity of atoms of carbon in solid solution.

An internal friction measurement commonly used is the natural logarithmic decrement between the successive oscillations of a sample submitted to a cyclical tension of torsion during the elastic regime. So, the equation of the logarithmic decrement can be expressed by [13-16]

$$
Q^{-1}=\frac{1}{n \pi} \ln \left(\frac{A_{i}}{A_{n+i}}\right)
$$

where " $n$ " is the number of cycles, " $A_{i}$ " is the oscillation amplitude after $i$-cycles. $Q^{-1}$ is the internal friction. Internal friction measurements can be used to evaluate phenomena which affect the mechanical performance of a material, such as the ageing after deformation, precipitation, changes of Young modulus or shear modulus, and phase transformations $[13,14]$. Some internal friction applications which involve phase transformations are the study of martensite in alloys with shape memory effect [17] and phase transformations in magnetic oxides [18]. Studies of mechanical relaxation spectroscopy in copper alloys [19] showed that the higher internal friction in martensite phase was caused by movement of twin boundaries and martensites plate boundaries.

Baraz et al. [20] found four internal friction peaks in an $18 / 8$ austenitic stainless steel in $1-\mathrm{Hz}$ frequency tests. The peaks were located around the following temperatures: $70^{\circ} \mathrm{C}$, $130^{\circ} \mathrm{C}, 220^{\circ} \mathrm{C}$, and $320^{\circ} \mathrm{C}$. The first and the last peaks were related to the deformed austenitic phase. The other two peaks were associated with the presence of $\alpha^{\prime}$-martensite.

Talonen and Hänninen [21] studying two AISI 304 and 304LN austenitic stainless steels carried out measurements of internal friction with a $1.8 \mathrm{~Hz}$ frequency. At the studied temperatures, $-196^{\circ} \mathrm{C}$ to $250^{\circ} \mathrm{C}$, two internal friction peaks were found in deformed materials. The first peak occurred at a $0^{\circ} \mathrm{C}$ and had its maximum value for samples rolled from $10 \%$ to $15 \%$. According to the authors, this peak is probably related to the existence of stacking fault and $\mathcal{\varepsilon}$-martensite. The other peak was found at a $130^{\circ} \mathrm{C}$ temperature and related 
TABLE 1: Chemical composition of the AISI 304 austenitic stainless steel (\% wt.).

\begin{tabular}{lcccccccc}
\hline $\mathrm{C}$ & $\mathrm{Si}$ & $\mathrm{Mn}$ & $\mathrm{Cr}$ & $\mathrm{Ni}$ & $\mathrm{Mo}$ & $\mathrm{N}$ & $\mathrm{Co}$ & $\mathrm{Cu}$ \\
\hline 0.06 & 0.39 & 1.31 & 18.09 & 8.03 & 0.04 & 0.033 & 0.10 & 0.07 \\
\hline
\end{tabular}

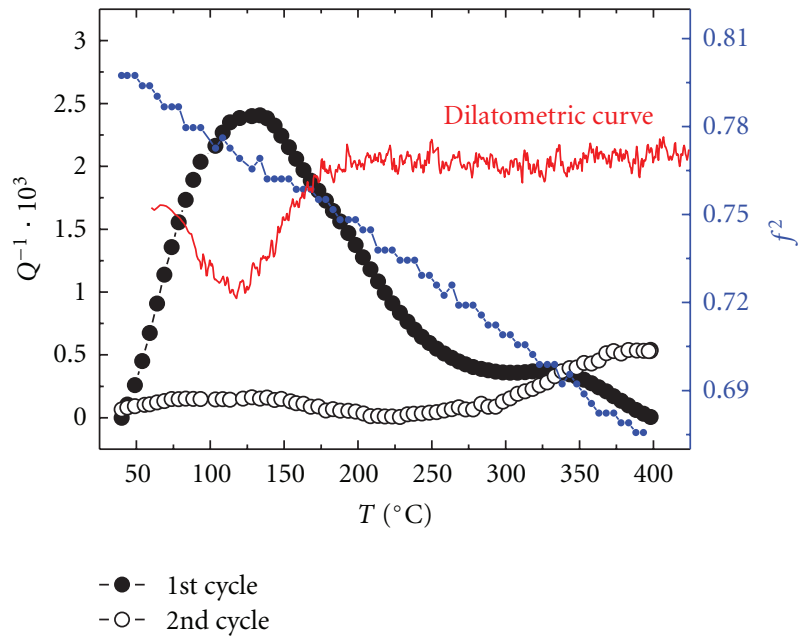

FIGURE 3: Internal friction spectra of sample with previous true deformation of 0.06 by tensile test at $-50^{\circ} \mathrm{C}$ during the first heating (in black) and the second heating cycle (hollow) in the same sample. The respective dilatometric curve from Figure 4(b) was added.

to the presence of $\alpha^{\prime}$-martensite. The authors indicated that this peak could be related to the tempered martensite. Ageing treatment at $200^{\circ} \mathrm{C}$ for 20 minutes diminished the damping of the studied materials [19].

Pinto et al. [22] working with an AISI 304 austenitic stainless steel observed three peaks of internal friction at temperatures $120^{\circ} \mathrm{C}, 220^{\circ} \mathrm{C}$, and $330^{\circ} \mathrm{C}$ for $1 \mathrm{~Hz}$. In 0.3 true strain, the $220^{\circ} \mathrm{C}$ peak increases proportionally with the content of $\alpha^{\prime}$-martensite.

\section{Experimental Procedure}

An AISI 304 austenitic stainless was used, and its chemical composition, given by the manufacturer, is shown in Table 1. The steel of commercial fabrication was produced by ArcelorMittal Inox Brazil, in $0.6 \mathrm{~mm}$ thick plates.

Different content of martensites was obtained with tensile tests performed in samples taken out of the parallel direction to the rolling direction. The specimens were made according to the ASTM646 standard [23]. The tests were carried out in an Instron 1125 universal machine with a temperature conditioning chamber model 3111 , which uses $\mathrm{CO}_{2}$ to be refrigerated and electrical resistance to be warmed. The tests were interrupted at the true deformations of 0.03 , $0.06,0.09$ and 0.12 . The specimen temperatures of $-50^{\circ} \mathrm{C}$, $-30^{\circ} \mathrm{C},-10^{\circ} \mathrm{C}$ and $20^{\circ} \mathrm{C}$ during the test were monitored through thermocouples welded on the sample.

The volumetric fraction of $\alpha^{\prime}$-martensite was determined through a Fischer MP3C ferritoscope. It was used the conversion factor 2 defined by Vilela et al. [24] found through comparisons with X-ray diffraction techniques, magnetic saturation balance, and optic and scanning probe microscopy.

X-ray diffraction spectra were obtained before and after deforming the samples. The measurements were carried out in the Shimadzu difractometer, XRD-6000 model, using $\mathrm{Cu}-\mathrm{K}_{\alpha}$ radiation to determine the presence of martensitic phases [25].

The metallographic preparation consisted on sanding and polishing with a $1-\mu \mathrm{m}$ diamond. Electrolytical polishing was adopted in order to eliminate superficial martensite induced during the preparation process which facilitated the chemical etching of the deformed samples. The sample as received was etched with glyceregia reagent and the ones deformed were etched with beraha II. The glyceregia reagent was constituted of 3 parts of $\mathrm{HCl}, 2$ parts of glycerol, and 1 part of $\mathrm{HNO}_{3}$. The beraha II reagent was constituted of $100 \mathrm{~mL}$ stock solution and $1 \mathrm{~g}$ of $\mathrm{K}_{2} \mathrm{~S}_{2} \mathrm{O}_{5}$. The stock solution was made of $48 \mathrm{~g}$ of $\mathrm{NH}_{4} \mathrm{HF}_{2}, 800 \mathrm{~mL}$ of distilled water and $400 \mathrm{~mL}$ of concentrated $\mathrm{HCl}$.

In order to verify reverse transformations in the 304 steel and also to relate the information obtained by the dilatometry with internal friction, dilatometric tests were performed in deformed samples from 0.03 to 0.12 at temperatures from $-50^{\circ} \mathrm{C}$ to $20^{\circ} \mathrm{C}$. The samples used in an Adamael Lhomargy LK02 dilatometer were measured with dimensions $12.0 \mathrm{~mm} \times 2.0 \mathrm{~mm} \times 0.6 \mathrm{~mm}$ and were cut on a parallel direction from the tensile tests. The dilatometry tests were performed in temperatures range from $50^{\circ} \mathrm{C}$ to $1000^{\circ} \mathrm{C}$ with a heating rate of $1.0^{\circ} \mathrm{C} / \mathrm{s}$.

Internal friction essays were performed in deformed samples from 0.03 to 0.12 at temperatures range from $40^{\circ} \mathrm{C}$ to $400^{\circ} \mathrm{C}$. Specimens were $50 \mathrm{~mm}$ long and $3 \mathrm{~mm}$ width and were cut in the rolling direction. The internal friction spectra were obtained in an inverted torsion pendulum. The oscillation frequency was $0.5-1 \mathrm{~Hz}$. After cooling until room temperature, a second cycle was done in the same temperature range aiming at verifying others events and supporting the data interpretation.

\section{Results and Discussion}

Figure 1(a) shows an optical micrograph of the steel as received, where the microstructure is constituted by equiaxial grains with annealing twins in gama phase. Figure 1(b) displays micrograph of a deformed sample, which is observed with thin laths of $\alpha^{\prime}$-martensite on the austenitic matrix. $\mathcal{E}$ martensite is difficult to be visualized by optical microscopy, but according to Mangonon and Thomas [6], $\alpha^{\prime}$-martensite is formed in crossings and in the $\varepsilon$-martensites plates intersections. Recent studies are indicating $[26,27]$ that the embryos of $\alpha^{\prime}$ are capable of nuclei from $\varepsilon$-martensite such as intersections of $\varepsilon$. Some authors $[28,29]$ have indicated in 


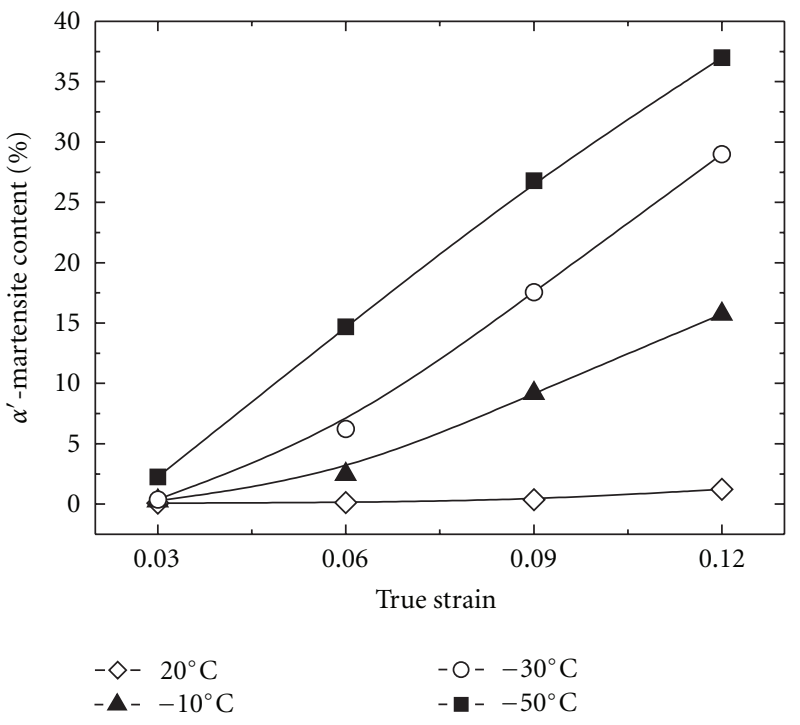

(a)

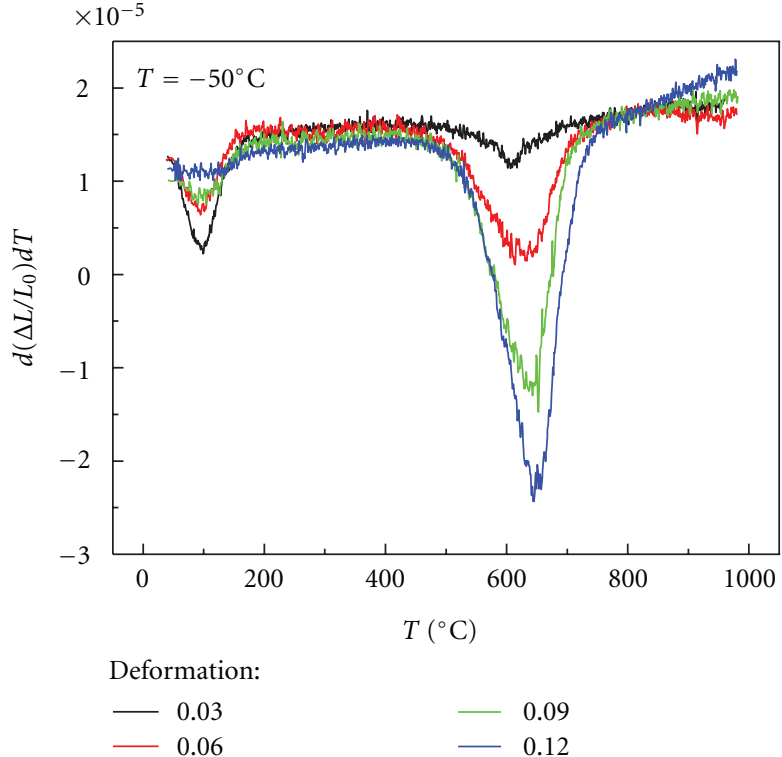

(b)

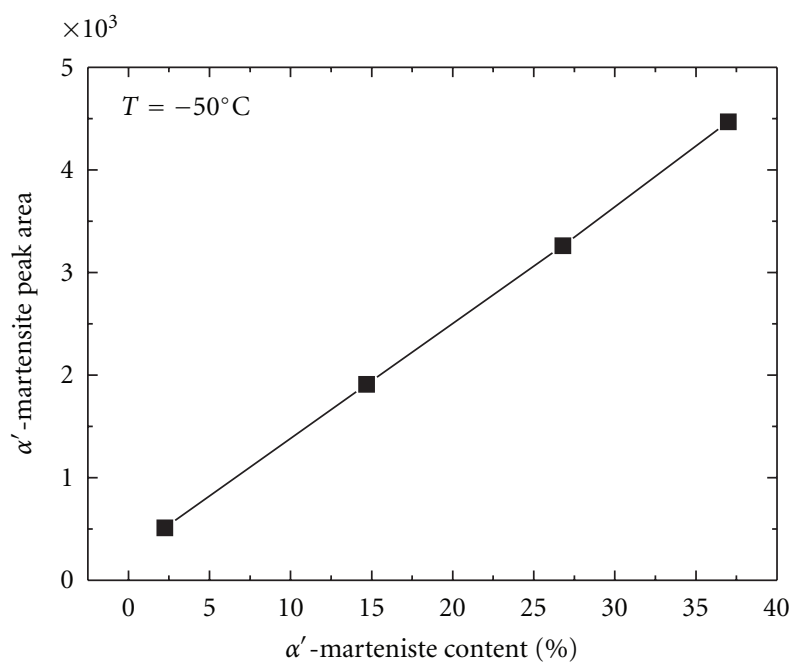

(c)

Figure 4: (a) $\alpha^{\prime}$-martensite content as result of applied strain. (b) Dilatometric curves of samples tensile deformed of 0.03, 0.06, 0.09, and 0.12 with previous deformation at $-50^{\circ} \mathrm{C}$. (c) Linear relation between $\alpha^{\prime}$-martensite peak area and content measured by ferritoscope in deformed specimen with previous deformation at $-50^{\circ} \mathrm{C}$.

the transformation route $\gamma \rightarrow \varepsilon \rightarrow \alpha^{\prime}$ that the $\varepsilon$-martensite acts as the precursors of $\alpha^{\prime}$. Other transformation routes are possible such as $\gamma \rightarrow \varepsilon, \gamma \rightarrow \alpha^{\prime}, \gamma \rightarrow$ deformation twin $\rightarrow \alpha^{\prime}[26,27]$.

Santos and Andrade [25] show the diffraction spectrum of the sample deformed 0.06 of true strain at $-10^{\circ} \mathrm{C}$. The presence of the $\mathcal{E}$ - and $\alpha^{\prime}$-martensites was observed. In Figure 2, the austenitic phase and epsilon and alpha prime martensite phases are detected.

Figure 3 shows a typical curve of internal friction obtained for a deformed AISI 304 austenitic stainless steel. The curve showed in black is of a deformed steel of 0.06 , by tensile test, at $-50^{\circ} \mathrm{C}$. Two peaks are observed on the $Q^{-1}$ curve as a result of the test temperature, the first one around $130^{\circ} \mathrm{C}$ and the other approached $350^{\circ} \mathrm{C}$. In the second heating cycle (hollow), curve (b), the peak around $130^{\circ} \mathrm{C}$ was not observed. However, there is, still, an elevation around $350^{\circ} \mathrm{C}$. The peak around $130^{\circ} \mathrm{C}$ is related to the reversion of the $\varepsilon$-martensite and the dilatometric studies (red) [30] indicate that the $\varepsilon \rightarrow \gamma$ transformation occurs. No significant changes in the measured frequency at square curve (blue) was observed.

Measurements of $\alpha^{\prime}$-martensite were perfomed with the ferritoscope and are shown in Figure 4(a). Notice that the amount of $\alpha^{\prime}$-martensite increases continuously with the applied deformation. It is also verified that lower temperatures are more appropriated to $\alpha^{\prime}$-martensites formation. 


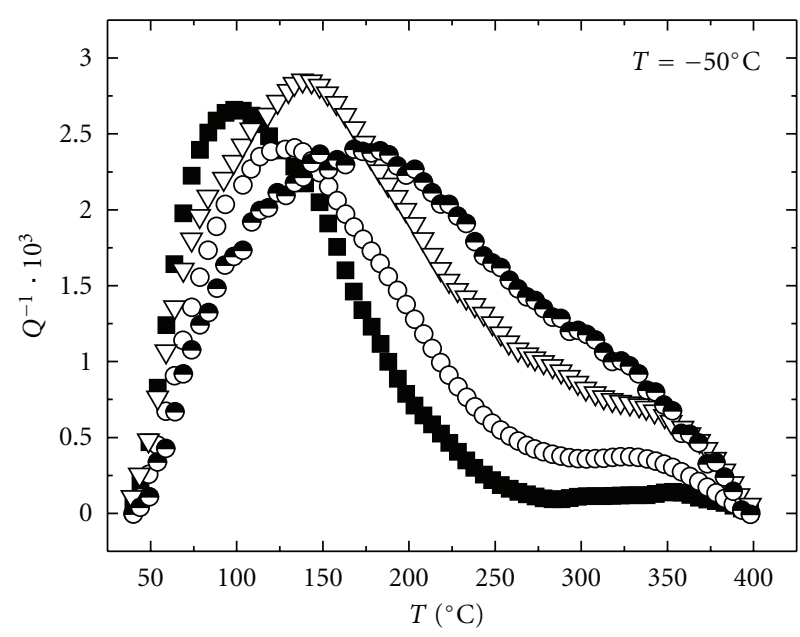

(a)

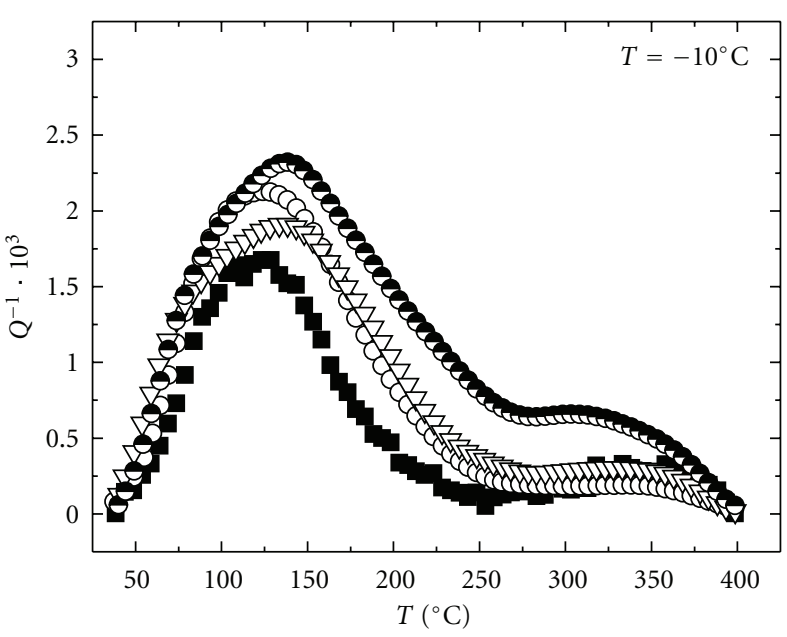

Deformation:

$\begin{array}{llll}\square & 0.03 & \nabla & 0.09 \\ 0 & 0.06 & \ominus & 0.12\end{array}$

(c)

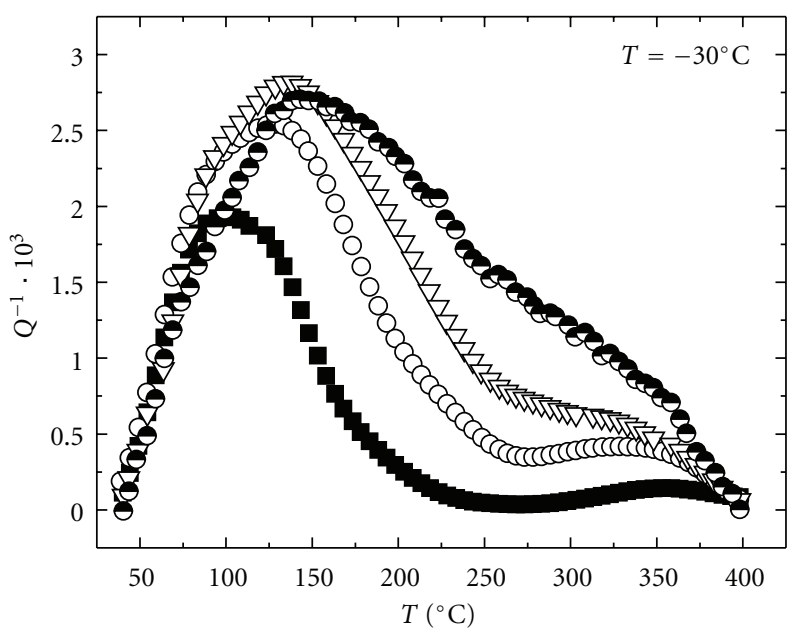

(b)

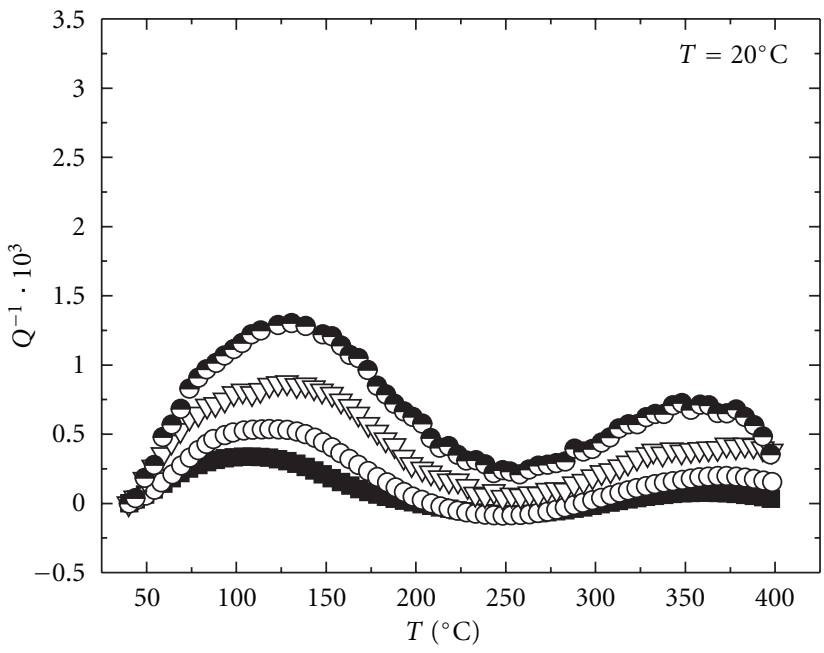

Deformation:

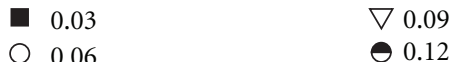

(d)

Figure 5: Internal friction spectra of samples with previous tensile true strain from $0.03,0.06,0.09$ and 0.12 introduced at the following temperatures; (a) $-50^{\circ} \mathrm{C},(\mathrm{b})-30^{\circ} \mathrm{C},(\mathrm{c})-10^{\circ} \mathrm{C}$ and (d) $20^{\circ} \mathrm{C}$.

Figure 4(b) shows dilatometric curves of samples deformed from 0.03 to 0.12 at $-50 . \varepsilon \rightarrow \gamma$ and $\alpha^{\prime} \rightarrow \gamma$ transformations are observed in temperatures range from $50^{\circ} \mathrm{C}$ to $200^{\circ} \mathrm{C}$ and from $500^{\circ} \mathrm{C}$ to $800^{\circ} \mathrm{C}$, respectively. It was observed that with lower deformations the $\varepsilon$-martensite forms in higher amount. When the deformation increases the $\varepsilon$-martensite amount diminishes and the $\alpha^{\prime}$-martensite amount increases.

Figure 4(c) shows the linear relationship $\alpha^{\prime}$-martensite measured by ferritoscope and the $\alpha^{\prime} \rightarrow \gamma$ transformation area calculated with the software Peaking Fitting Origin 6.1 from dilatometric curves in the sample deformed at $-50^{\circ} \mathrm{C}$. The samples deformed at the other temperatures showed the same behavior. For samples deformed at $20^{\circ} \mathrm{C}$, the $\alpha^{\prime}$-martensite content is so small that the $\alpha^{\prime} \rightarrow \gamma$ transformation peak was not detected for 0.03 and 0.06 true strains (Figure 4(a)). It is possible to observe the direct proportionality among the amount of $\alpha^{\prime}$-martensite and the $\alpha^{\prime} \rightarrow \gamma$ transformation peak area. So, the transformation behavior is identical to the one indicated by determinations with the ferritoscope, the quantity of $\alpha^{\prime}$-martensite increases with deformation. Das and Tarafder [26] studying an AISI 304LN stainless steel showed that the amount of $\alpha^{\prime}$ martensite increases very rapidly with true strain in a linearly proportional manner. In comparison between the curves for different strain rates, it was observed that while the increase in strain rate favours martensite formation at low strain level, the maximum amount of martensite formed due to tensile deformation is reduced with the increase in the strain rate. 


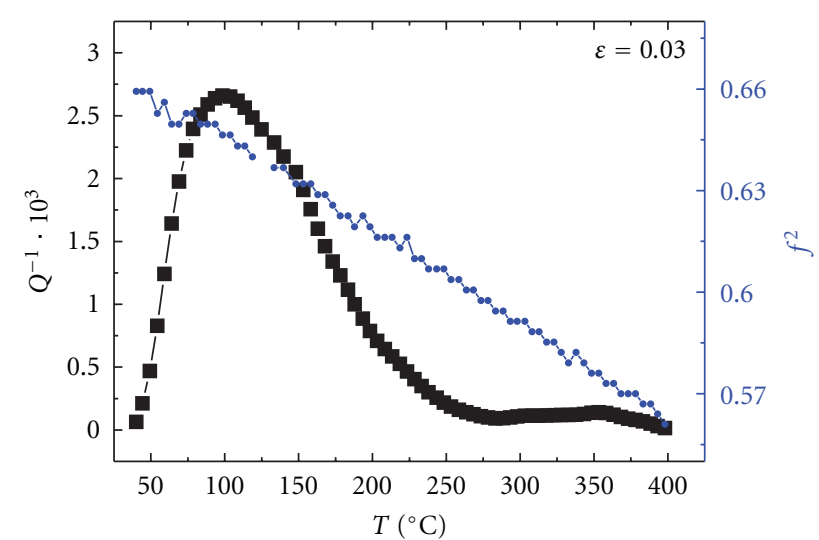

(a)

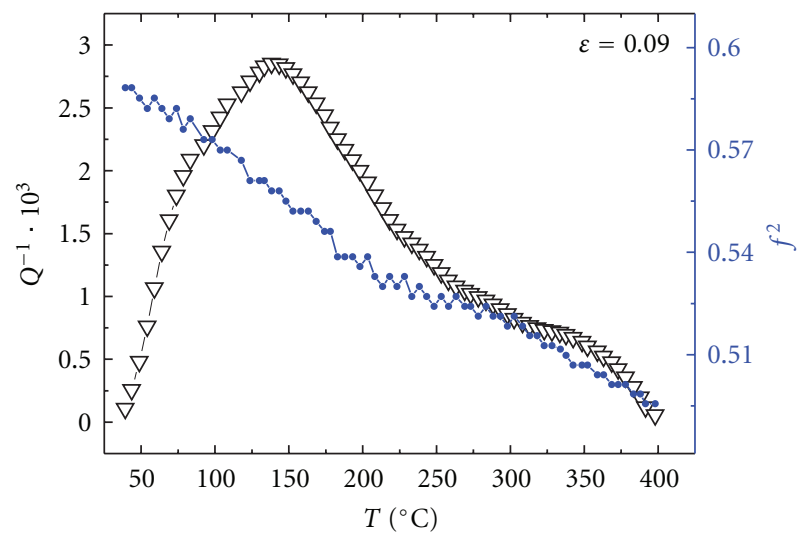

(c)

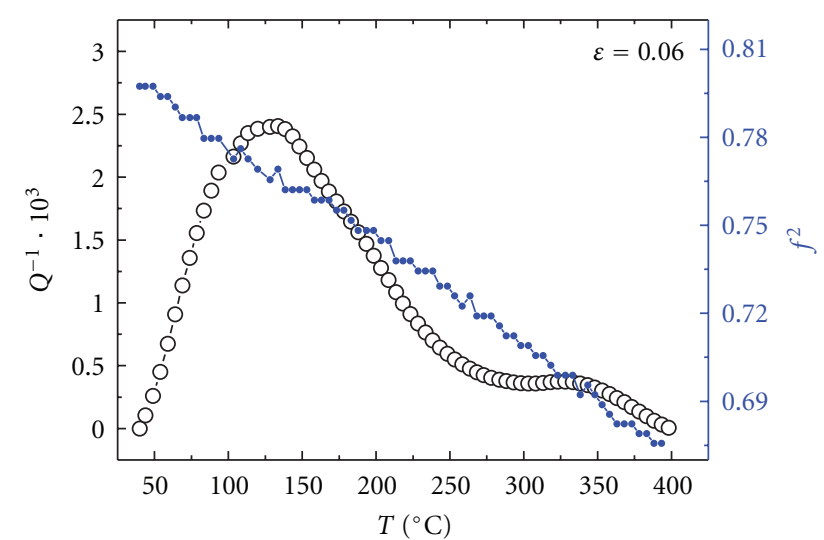

(b)

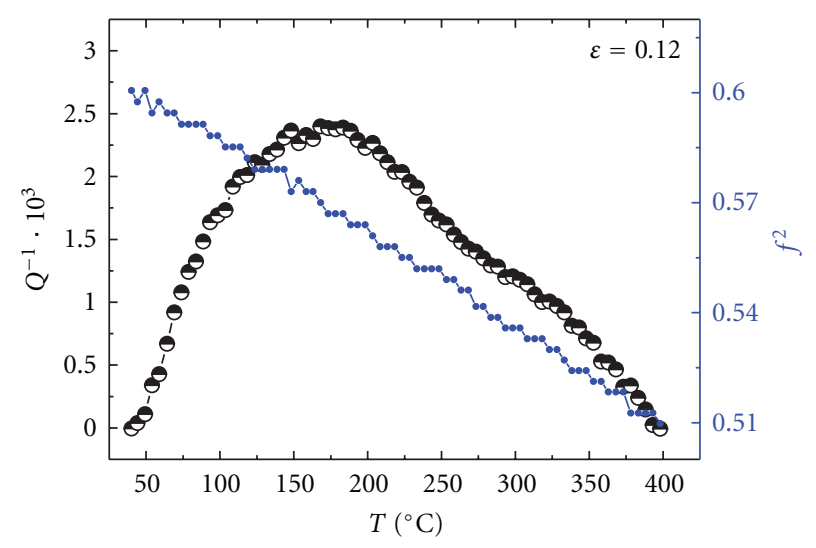

(d)

FIGURE 6: Internal friction spectra of samples with previous tensile true strain from $0.03,0.06,0.09$, and 0.12 introduced at $-50^{\circ} \mathrm{C}$ showing the measured frequency at square curve.

Figure 5(a) shows the spectra of internal friction of deformed samples of 0.03 to 0.12 at $-50^{\circ} \mathrm{C}$. It is possible to observe that deformed sample of 0.03 , a higher quantity of $\mathcal{E}$-martensite aligns the internal friction spectrum at lower temperatures. With the increase of the $\alpha^{\prime}$-martensite content in the specimen, which rises with the increase of deformation, part of the internal friction spectrum moves up to higher temperatures, this sample still shows significant amount of $\varepsilon$-martensite. With higher deformation, 0.09 , the amount of $\varepsilon$-martensite is very small, while the quantity of $\alpha^{\prime}$-martensite is much higher, thus the peak displacement is more distinct and its height increases. In 0.12 deformed samples, the $\alpha^{\prime}$-martensite content increases very much, in detriment of $\varepsilon$, and the peak shows a larger displacement, aligned in a region where there is a peak related exclusively to the $\alpha^{\prime}$-martensite [22]. The data of dilatometry and internal friction curves for samples with these deformations and $-50^{\circ} \mathrm{C}$ temperature in this steel (Figure $4(\mathrm{~b})$ ) show that the first peak is related to the presence of $\varepsilon$ and $\alpha^{\prime}$ in a coordinate way, moreover, the presence of $\alpha^{\prime}$-martensite arises in detriment of $\varepsilon$-martensite.

In deformed samples at $-30^{\circ} \mathrm{C}$ (Figure $5(\mathrm{~b})$ ), it is possible to observe that the first peak, which shows larger amounts of $\varepsilon$-martensite, starts with a smaller height. For samples deformed of 0.06 , the height rises as result of increase $\mathcal{E}$ - and $\alpha^{\prime}$-martensite content. At 0.09 of deformation, it displaces to higher temperatures due to larger quantities of $\alpha^{\prime}$. At 0.12, it tends to align with the peak related to $\alpha^{\prime}$, which occurs at higher deformations. Samples deformed at $-10^{\circ} \mathrm{C}$ show the same behavior (Figure 5(c)).

In the samples deformed at $20^{\circ} \mathrm{C}$ (Figure $5(\mathrm{~d})$ ), it is possible to observe that samples deformed at 0.03 , the appearing of the first peak aligns with the $\varepsilon \rightarrow \gamma$ transformation region, and with the increase of deformation it is verify that the peak height is related to the quantity of $\varepsilon$ that reverts to $\gamma$. At higher deformations, the peak starts a soft displacement due to the beginning of $\alpha^{\prime}$-martensite formation, accompanied by an increase in the friction level around $250^{\circ} \mathrm{C}$ and the $350^{\circ} \mathrm{C}$ peak appearance.

The internal friction peak around $350^{\circ} \mathrm{C}$ increases with deformation and it becomes more evident with higher deformations. Baraz et al. [20] was found this peak working with an austenitic stainless steel with a composition very close to the one which was studied in this work. The authors related to the deformed austenitic structure. Our studies suggest that this peak is also related to the presence of $\alpha^{\prime}$ martensite, that is, to a mixture of deformed $\gamma$ and interfaces of $\alpha^{\prime}$ in austenite.

Figure 6 shows the internal friction and the measured frequency at square curve for samples deformed at $-50^{\circ} \mathrm{C}$. 
No significant changes in the measured frequency at square curve was observed. But Figure 4 shows clearly the concordance between the internal friction first peak and the $\varepsilon \rightarrow \gamma$ transformation, which occurs in the same region. Samples deformed in other temperatures show the same behavior.

\section{Conclusions}

The $\varepsilon$-martensite forms first in the deformed samples, giving place to $\alpha^{\prime}$-martensite formation, evidencing the $\gamma \rightarrow \mathcal{\varepsilon} \rightarrow$ $\alpha^{\prime}$ mechanism on this steel, for the -50 to $20^{\circ} \mathrm{C}$ range of temperature and deformation conditions.

Measurements with the ferritoscope allowed checking the increase of $\alpha^{\prime}$-martensite with the applied deformation. The same effect was detected with the dilatometric tests that helped to verify the diminishing of $\varepsilon$-martensite as result of the $\alpha^{\prime}$-martensite increase, corroborating the information obtained from the internal friction spectra.

The internal friction spectra of the AISI 304 austenitic stainless steel, containing strain-induced $\varepsilon$ - and $\alpha^{\prime}$ martensite can be interpreted considering the occurrences of three distinct phenomena which over lag in the same temperatures range.

The first internal friction peak is related to sum of the amount of $\varepsilon$ and $\alpha^{\prime}$-martensites. For low deformations, it aligns around $130^{\circ} \mathrm{C}$ and it is related only to the $\varepsilon \rightarrow \gamma$ reverse transformation. This transformation was evaluated by dilatometric tests that showed a reversion of the $\mathcal{E}$ martensite occurring in temperature range from $50-200^{\circ} \mathrm{C}$.

Part of the internal friction spectrum at temperatures in the $40^{\circ} \mathrm{C}-300^{\circ} \mathrm{C}$ range displaces to higher temperatures while the $\alpha^{\prime}$-martensite content increases. The displacement of the first internal friction peak to higher temperatures is a consequence of the increase of $\alpha^{\prime}$-martensite quantity in detriment of $\varepsilon$-martensite.

The internal friction peak situated $350^{\circ} \mathrm{C}$ increases with the applied deformation. The effect starts more evidently in deformed samples at 0.09 for all deformation temperatures used in this work. This last peak is probably related to deformed austenite and the presence of $\alpha^{\prime} / \gamma$ interfaces.

Measurements of frequency at square curve do not indicate any significant changes in the deformed samples. However, there are a clear concordance between the internal friction first peak and the $\varepsilon \rightarrow \gamma$ transformation, which occurs in the same region.

\section{Acknowledgments}

The authors are indebted to CNPq and FINEP for financial support. T. F. A. Santos and M. S. Andrade thank CNPq and Fapemig, respectively, for scholarships.

\section{References}

[1] A. F. Padilha and P. R. Rios, "Decomposition of austenite in austenitic stainless steels," ISIJ International, vol. 42, no. 4, pp. 325-337, 2002.

[2] C. Blanc, "Mécanismes de déformation des aciers inoxydables austénitiques," in Les Aciers Inoxydables, P. Lacombe, B.
Baroux, and G. Beranger, Eds., Éditions de Physique, pp. 611617, Courtaboeuf, France, 1990.

[3] K. Guy, E. P. Butler, and D. R.F. West, "Epsilon and alpha prime martensite formation and reversion in austenitic stainless steels," Journal de Physique, vol. 43, no. 4, pp. 575-580, 1982.

[4] G. J. Fischer and R. J. Maciag, "The wrought stainless steels," in Handbook of Stainless Steels, D. Peckner and I. M. Bernstein, Eds., vol. 1, pp. 1.1-1.9, McGraw-Hill, New York, NY, USA, 1977.

[5] L. F. M. Martins, R. L. Plaut, and A. F. Padilha, "Effect of carbon on the cold-worked state and annealing behavior of two $18 \mathrm{wt} \% \mathrm{Cr}-8 \mathrm{wt} \% \mathrm{Ni}$ Austenitic stainless steels," ISIJ International, vol. 38, no. 6, pp. 572-579, 1998.

[6] L. Mangonon and G. Thomas, "Martensite phases in 304 stainless steel," Metallurgical and Materials Transactions, vol. 1, no. 6, pp. 1577-1586, 1970.

[7] L. J. Baker, J. D. Parker, and S. R. Daniel, "The use of internal friction techniques as a quality control tool in the mild steel industry," Journal of Materials Processing Technology, vol. 143144, no. 1, pp. 442-447, 2003.

[8] M. S. Andrade, O. A. Gomes, J. M. C. Vilela, A. T. L. Serrano, and J. M. D. Moraes, "Formability evaluation of two austenitic stainless steels," Journal of the Brazilian Society of Mechanical Sciences and Engineering, vol. 26, no. 1, pp. 47-50, 2004.

[9] V. Taylan, R. H. Wagoner, and J. K. Lee, "Formability of stainless steel," Metallurgical and Materials Transactions A, vol. 37, pp. 1875-1880, 2006.

[10] A. K. De, D. C. Murdock, M. C. Mataya, J. G. Speer, and D. K. Matlock, "Quantitative measurement of deformation-induced martensite in 304 stainless steel by X-ray diffraction," Scripta Materialia, vol. 50, no. 12, pp. 1445-1449, 2004.

[11] B. Petit, N. Gey, M. Cherkaoui, B. Bolle, and M. Humbert, "Deformation behavior and microstructure/texture evolution of an annealed 304 AISI stainless steel sheet. Experimental and micromechanical modeling," International Journal of Plasticity, vol. 23, no. 2, pp. 323-341, 2007.

[12] A. K. De, J. G. Speer, D. K. Matlock, D. C. Murdock, M. C. Mataya, and R. J. Comstock Jr., "Deformation-induced phase transformation and strain hardening in type 304 austenitic stainless steel," Metallurgical and Materials Transactions, vol. 37, no. 6, pp. 1875-1886, 2006.

[13] I. G. Ritchie, P. M. Mathew, Z. I. Pan, C. Osborne, and J. K. Prikryl, "Mechanical relaxation spectroscopy in steel wire research," Wire Journal International, pp. 201-218, 1989.

[14] A. S. Nowick and B. S. Berry, Anelastic Relaxation in Crystalline Solids, Academic Press, New York, NY, USA, 1972.

[15] R. E. Reed-Hill, Physical Metallurgy Principles, PWS-Kent, Boston, Mass, USA, 1992.

[16] P. Shewmon, Diffusion in Solids, Minerals, Metals \& Materials Society, Philadelphia, Pa, USA, 1989.

[17] N. Yu, G. S. Koval, J. V. Firstov, J. Van Humbeeck, L. Delaey, and W. Y. Jang, " $\mathrm{B}_{2}$ intermetallic compounds of Zr. new class of the shape memory alloys," Journal of Physics, vol. 5, no. 8, p. 1103, 1995.

[18] R. Zenati, C. Bernard, C. Calmet, S. Guillemet, G. Fantozzi, and B. Durand, "Internal friction investigation of phase transformation in nearly stoichiometric $\mathrm{LaMnO}_{3+\delta}$," Journal of the European Ceramic Society, vol. 25, no. 6, pp. 914-935, 2005.

[19] J. Perkins, Shape Memory Effects in Alloys, Metallurgical Society of AIME, San Diego, Calif, USA, 1975.

[20] V. R. Baraz, S. V. Grachev, and L. D. Rol'shchikov, "Internal friction in non-stable austenitic steels," Steel in the USSR, vol. 2, pp. 670-672, 1972. 
[21] J. Talonen and H. Hänninen, "Damping properties of austenitic stainless steels containing strain-induced martensite," Metallurgical and Materials Transactions A, vol. 35, no. 8, pp. 2401-2406, 2004.

[22] T. B. Pinto, O. A. Gomes, J. M. C. Vilela, M. S. Andrade, A. L. Serrano, and J. M. D. de Moraes, "Relationship between internal friction and strain induced martensite amount in an AISI 304 stainless steel," in Proceedings of the 58th Annual International Congress of the Brazilian Association of Metallurgy and Materials, pp. 3137-3144, Rio de Janeiro, Brazil, July 2003.

[23] ASTM Standard E-646, 1993.

[24] J. M. C. Vilela, N. J. L. Oliveira, M. S. Andrade, B. M. Gonzalez, C. E. R. Santos, and J. M. D. de Moraes, "Metallographic analysis of stainless steels after deformation at different temperatures," in Proceedings of the 56th Annual International Congress of the Brazilian Association of Metallurgy and Materials, pp. 510-519, Belo Horizonte, Brazil, 2001.

[25] T. F. A. Santos and M. S. Andrade, "Dilatometric evaluation of strain-induced martensite reversion in AISI 304 austenitic stainless steel," Matéria, vol. 13, no. 4, pp. 587-596, 2008.

[26] A. Das and S. Tarafder, "Experimental investigation on martensitic transformation and fracture morphologies of austenitic stainless steel," International Journal of Plasticity, vol. 25, no. 11, pp. 2222-2247, 2009.

[27] K. H. Lo, C. H. Shek, and J. K. L. Lai, "Recent developments in stainless steels," Materials Science and Engineering R, vol. 65, pp. 39-104, 2009.

[28] N. Gey, B. Petit, and M. Humbert, "Electron backscattered diffraction study of $\varepsilon / \alpha$ ' martensitic variants induced by plastic deformation in 304 stainless steel," Metallurgical and Materials Transactions A, vol. 36, no. 12, pp. 3291-3299, 2005.

[29] M. Humbert, B. Petit, B. Bolle, and N. Gey, "Analysis of the $\gamma-\varepsilon-\alpha^{\prime}$ variant selection induced by $10 \%$ plastic deformation in 304 stainless steel at $-60^{\circ} \mathrm{C}$," Materials Science and Engineering A, vol. 454-455, pp. 508-517, 2007.

[30] T. F. A. Santos, M. S. Andrade, and A. L. R. Castro, "Influence of heating rate on the reversion of strain-induced martensite in AISI 304 austenitic stainless steel," Revista Escola de Minas, vol. 62, no. 1, pp. 53-58, 2009. 

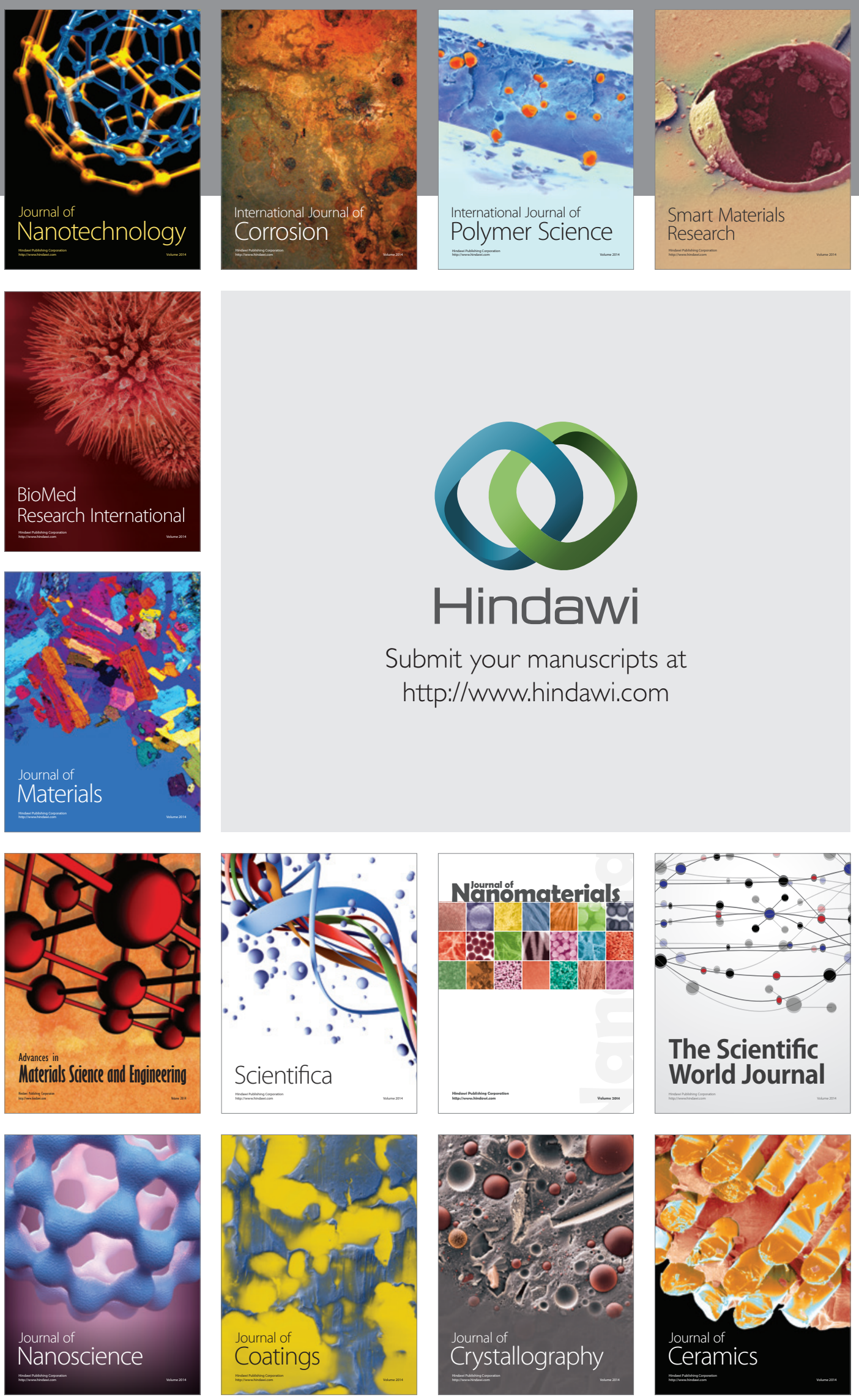

The Scientific World Journal

Submit your manuscripts at

http://www.hindawi.com

\section{World Journal}

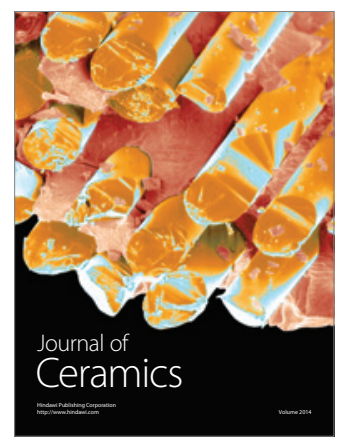

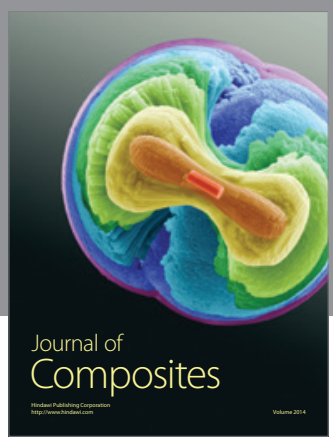
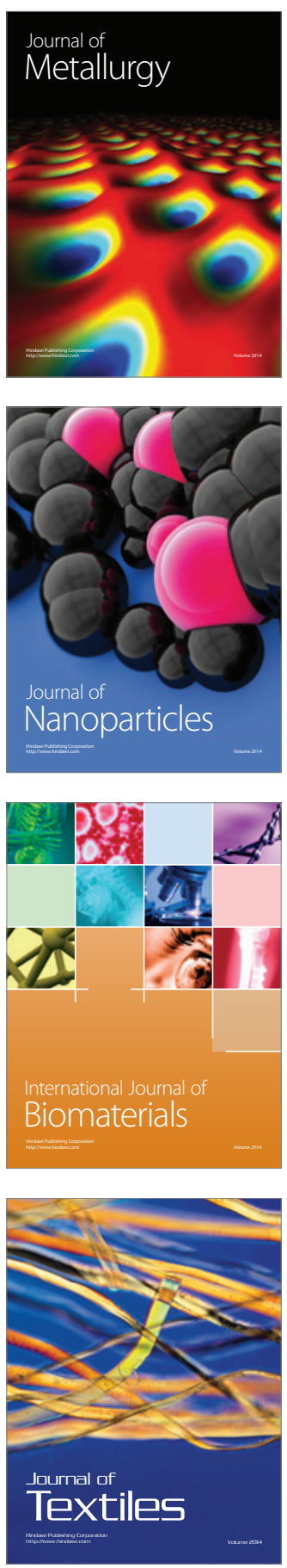